\title{
Alguns aspectos analíticos nas pesquisas da violência na América Latina ${ }^{1}$
}

\author{
MICHEL MISSE ${ }^{I}$
}

$\mathrm{P}$ RETENDO PROPOR, neste artigo, em linhas gerais e introdutórias, alguns dos principais desafios analíticos postos pelas pesquisas da violência na América Latina, especialmente quando as observamos no contexto global. O desafio analítico mais abrangente decorre, a meu ver, da contradição entre os ideais de modernização do Estado na América Latina, um imaginário construído numa linha evolucionista, que acredita poder "realizar" ou "alcançar", algum dia no futuro, o modelo de Estado europeu-ocidental ou norte-americano, e a interminável resistência a esses ideais que surgem das formas efetivas de relações de poder e formas de mercado e capital existentes. A minha tese é que a política dos Estados latino-americanos para controlar a violência realimenta a própria violência. São, em geral, respostas anacrônicas e disfuncionais, incapazes de perceber as diferenças constitutivas dos problemas que pretendem enfrentar. Mas são, por outro lado, funcionais para a manutenção, a fórceps, do establishment de desigualdade social de fora a fora.

\section{O problema}

A América Latina tem menos de dez por cento da população mundial mas produz um terço dos homicídios do mundo. Segundo as Nações Unidas, 14 dos 20 países mais perigosos do mundo estão na América Latina e no Caribe. Em 2017, 65 mil pessoas foram assassinadas no Brasil. Na Colômbia, uma pessoa foi assassinada a cada dez minutos em 2015. A polícia brasileira mata mais que qualquer outra polícia do mundo, mas também morre mais que em qualquer outra parte. Os dados são impressionantes, mas vou poupá-los de continuar a apresentá-los. ${ }^{2}$ Interessa-me aqui discutir como compreender essa violência e os problemas analíticos e de pesquisa postos para quem se coloca essa tarefa. Vejamos por partes, a começar pela constatação de que não é possível discutir-se violência sem referência ao Estado. Uma segunda e paradoxal constatação é que os números são números de guerras, mas não há guerras, nem entre Estados, nem guerra civil - ao menos no sentido convencional de dois ou mais lados em luta para obter a vitória ou o armistício. Havia algo assim na Colômbia e na Guatemala, mas já não há da mesma forma. Há conflitos armados envolvendo grupos vinculados a mercados ilegais de diferentes tipos e também grupos para- 
estatais que os combatem, além, naturalmente, das forças do Estado, mas não há reconhecimento de que esses grupos tenham conteúdo político ou ideológico nítido ou objetivos coletivos. Não há vitória ou armistício possível, já que esses conflitos estão capturados pelo processo de criminalização.

Temos batalhas, mas não temos guerra. Temos crimes, mas não temos Estado capaz de controlá-los ou regulá-los a níveis aceitáveis. ${ }^{3}$ A extensão da violência difusa no Brasil, que vem aumentando há pelo menos quatro décadas, diferencia-se do caso do México ou da Colômbia onde cartéis atacadistas de cocaína e outras drogas ilícitas lutam entre si pelos lucros milionários desse comércio. Gangues que controlam o varejo de drogas na América Central praticam também crimes violentos como no caso das maras de El Salvador, das facções brasileiras, das pandillas venezuelanas, peruanas e colombianas. Grupos paramilitares e parapoliciais praticam a extorsão, desalojam moradores e enfrentam as gangues com mais violência. Os homicídios crescem em toda a América Latina, com a única exceção - por enquanto - do Chile. Até mesmo a Argentina e o Uruguai, que tinham as taxas mais baixas de homicídios até dez anos atrás, já apresentam sensível crescimento da violência.

É preciso reconhecer uma disjunção - diferencial entre os países analisados - entre Estado e sociedade. É essa disjunção, a meu ver, que explica em grande parte os níveis de corrupção na América Latina. Sem compreendê-la, fica também difícil compreender a persistência dos mercados informais e ilegais. Essa disjunção resulta dos altos níveis de desigualdade social e pobreza, que alimentam alternativas aquisitivas vantajosas, ainda que ilegais, nessas sociedades e dos problemas de legitimação do Estado na América Latina, mesmo sob regimes democráticos. ${ }^{4}$

Tudo isso, evidentemente, coloca em primeiro plano a questão da soberania do Estado na América Latina e da sua concorrência - por assim dizer com outras soberanias intrassocietais. ${ }^{5} \mathrm{O}$ incremento da violência desvelou a questão do Estado na América Latina e desse modo desvelou também um tipo de disjunção de Estado e sociedade nascida da histórica fratura da própria sociedade em suas diferenças internas e contradições. A maior parte das populações latino-americanas não poderia ser classificada pelo parâmetro europeu ou norte-americano de cidadania, para dizer o mínimo. O volume de exclusão social, desigualdade de direitos civis, políticos e sociais, pobreza persistente e incapacidade de acessar canais de representatividade no Estado explicam uma parte importante daquela disjunção, bem como das formas de normalização repressiva que o Estado desenvolveu para lidar com essas populações.

\section{Violência, crime e corrupção como operadores analíticos}

Violência é um conceito escorregadio (Walby, 2013; Imbush, 2003; Misse, 2016). Em seu núcleo mais antigo e amplamente partilhado significa violação da integridade física de um indivíduo ou grupo. $O$ uso da palavra geralmente representa o sentido de uma agressão a alguém. Mas com o tempo foi ganhando 
significado mais abrangente e dependente de uma disputa de legitimação. $\mathrm{O}$ conceito de violência amplia-se com a ampliação do significado do que seja civilizado e pacífico. O processo civilizatório de que fala Norbert Elias é exatamente coincidente com a definição do que seja violência em cada época. Uma consulta ao Ngram do Google Livros permite verificar que, além da violência física, o termo violência vem ganhando abrangência de significado desde pelo menos os anos 1960. O volume de citações da palavra "violence" em livros da língua inglesa mais que dobrou entre 1960 e 2000 , sem qualquer queda na série. O volume de citações da palavra "violência" na língua espanhola triplicou no mesmo período, deixando, curiosamente, a palavra "crime" praticamente estacionada, o que demonstra uma autonomia e maior abrangência da referência à violência em relação ao uso da palavra "crime". É preciso atentar para esse processo, ele é uma das dimensões do que tenho chamado de "acumulação social da violência" (Misse, 1999; 2019).

Quando o pesquisador utiliza a noção de violência para descrever um evento ou incorporar em sua análise uma representação social, ele precisa estar consciente de que o uso dessa palavra é performático e não apenas descritivo, com consequências nitidamente normativas. Se essa for a intenção, é preciso sempre ter o cuidado de contrabalançar a análise acrescentando a outra violência que essa violência convoca quando é nomeada. Toda atribuição de algo ou de alguém como violento implica a demanda, consciente ou não, de uma contraviolência que impeça ou evite a continuidade da violência apontada. Essa implícita contraviolência pode ser legal ou não, como pode ser legítima ou não. Operar com o conceito de violência carrega essas dificuldades. Como advertiu Willem Schinkel, em seu livro sobre os "aspectos da violência", dependendo do uso que der ao conceito, o pesquisador pode produzir efeitos de violência mesmo sem o desejar (Schinkel, 2010).

Em várias das representações sociais da violência contemporânea, sejam da mídia, sejam do senso comum intelectual, encontramos implícita uma denúncia do conflito, como se esse pudesse ser substituído por uma competição cavalheiresca regulada. Se, por um lado, as acusações de violência, feitas a um Outro, reclamam tolerância às diferenças, por outro, parecem pautar conflitos identitários, de raça, gênero, religião ou nação que podem também incorporar efeitos de violência.

Tudo isso tem feito, por um lado, ampliar o significado de violência para cursos de ação que antes não eram assim interpretados. E por outro, tem incorporado demandas de violência - legítima ou ilegítima, legal ou não - para controlar e regular essas novas violências. Um círculo vicioso acumulativo de violências define o novo ambiente social.

Violência, conflito e poder estão emaranhados numa disputa de sentido na qual cada sujeito buscará legitimação para sua soberania, a qualquer custo, contra a soberania do outro. E isso incorpora necessariamente a linguagem e a comunicação na violência, ao contrário de derrotá-las ou denegá-las. 
Quando uma soberania recebe reconhecimento suficiente ela irá recepcionar o sentido comum e, modificando-o para sua autopreservação, classificar o que será intolerável para a sua hegemonia. É o que deverá ser criminalizado.

Aqui reencontramos outro termo de fácil sentido e também muito escorregadio, o crime, os crimes, o criminal. O que será crime e o que não será, o que era crime e o que deixará de sê-lo passará por disputas morais intermitentes, como bem sublinhou Howard Becker. Mas não se pense que esse processo se extingue assim que se defina um set institucionalizado do que será criminalizado. No cotidiano concreto das acusações e denúncias, o processo de criminalização ganha vida e os procedimentos que irão definir realmente o que será criminado - sejam procedimentos do Estado, sejam de outras soberanias - irão depender não só de avaliações morais, como também de diferentes medidas de interesses. De forma ainda mais incisiva, o processo de incriminação de supostos sujeitos do crime passará por provas diferenciais cuja tendência será aniquilar qualquer pretensão igualitária quanto mais desigual for a sociedade. Separado de suas condições sociais, o crime e o criminoso serão submetidos a procedimentos que, mesmo quando igualitários, reproduzirão a desigualdade de sua produção. Nas sociedades muito desiguais quanto às condições sociais de escolha dos destinos individuais, a tendência será classificar preventivamente o suposto sujeito do crime em duas categorias, os perigosos e os não perigosos, os puníveis e os elimináveis. A reificação de uma relação social - o crime - no sujeito completa o processo da sujeição criminal, isto é, da fabricação social do criminoso como bandido. Esse, o bandido, o sujeito identificado com o crime e a violência, só se salvará se abandonar sua identificação com o crime, seja através de conversão religiosa, seja através de processos de "ressocialização". Do contrário, será definitivamente excluído da vida comum, deixado à morte ou morto. ${ }^{6}$

\section{A situação atual da violência na América Latina}

Assim como é preciso reconhecer que o significado de violência vem se ampliando junto com o processo civilizatório e que o conceito de violência está ainda sendo produzido em sua polissemia, é necessário não subestimarmos, no conceito, aquilo que provoca maior reação moral e atinge de forma mais aguda a sensibilidade moral de uma sociedade e de uma época. Nesse sentido, o homicídio e as diversas formas de crueldade impingidas a um indivíduo ou grupo vem a constituir, na modernidade que cultiva o valor da vida e da dignidade do indivíduo, a violência mais evidente e inaceitável tipificada nos crimes mais puníveis. Entretanto, também aqui há paradoxos e contextualizações de cada caso e é preciso estar atento à produção de sentido local ou contingente. Uma reação armada considerada legítima pode praticar a violência dentro de determinados parâmetros, legais ou não. Aqui é preciso distinguir, dentre as violências armadas, aquelas que são classificados entre as guerras, convencionais ou de guerrilhas, e aquelas que cairão na classificação dos crimes e das crueldades. 
O que produz mais repulsa moral? Quem classifica? Temos aqui um primeiro problema. Em geral, a classificação já está estabelecida na representação social, mas há eventos cuja classificação ainda está sendo disputada. No Rio de Janeiro, os conflitos armados entre facções do tráfico de drogas, ou entre elas e milícias parapoliciais ou com a polícia utilizam-se de armas de guerra e produzem muitas mortes em meio urbano. Os que defendem que devem ser classificados como "guerra” são também os que legitimarão o extermínio dos adversários. Os que interpretam como criminalidade violenta defenderão um tratamento policial e judiciário adequado às leis, ainda que saibam da baixa eficiência legal do sistema de justiça. Cabe ao pesquisador recolher os vários sentidos dessa disputa e não apenas se posicionar perante elas, escolhendo um dos lados, ainda que o faça para si. Esse problema remete à questão geral que estamos tratando e que deve ser enfrentada como um problema mais geral da relação da sociedade com o Estado na América Latina, mesmo quando não é esse o objeto da pesquisa. Esquecer essa questão mais geral pode induzir o pesquisador a tratar o problema que está investigando como se estivesse em outra sociedade, onde a classificação desse tipo de evento não é mais objeto de disputa e onde há grande consenso na representação social quanto a quem exerce a soberania. ${ }^{7}$

Um importante indicador dessas diferenças quanto à soberania e quanto à relação da sociedade com o Estado pode ser a medida do que é representado como "corrupção". O termo está associado, na modernidade, a um crime contra o bem comum sempre que o bem comum está sob a proteção do Estado. Em outros termos, a corrupção sempre envolve algum tipo de prejuízo, moral ou material, à sociedade, através de uma fraude ao Estado. Não se aplica a fraudes ou crimes entre particulares, mas a fraudes praticadas contra o Estado. É um suposto que a relação do Estado com a sociedade é estreita e que a base de legitimidade é ampla e consensual. Naturalmente, estamos falando de Estado e não de governos ou do sistema político, o que remete a um argumento quanto à moral cívica. Dito de outro modo, a corrupção nomeia um ataque ao tipo ideal de Estado quanto à legitimidade, quanto à sua relação estreita com a sociedade e quanto à moral cívica que sustenta o sentido comum desse crime. Estamos aqui no âmbito da soberania mais consensual do Estado moderno, democrática e típico-ideal, ainda que cheia de problemas e dificuldades.

Há muitas modalidades de explicações para a disjunção da sociedade com o Estado na América Latina, desde a ênfase na herança patrimonialista ibérica até as abordagens pós-coloniais sobre "sociedade política" e a tradicional visão marxista. Há muitas diferenças de país a país, mas há em comum o que tem sido interpretado como uma "fraqueza" do Estado ou a ineficácia das agências e instituições estatais encarregadas da regulação do mercado, do controle das forças armadas e da administração da justiça. Democracias de "baixa densidade", na expressão de O’Donnell, tem se alternado a ditaduras civis ou militares, populistas ou autoritárias, em quase todos os países latino-americanos. 
Nesse ambiente, as práticas que, no Estado moderno, são denunciadas como corrupção parecem ganhar uma abrangência tão grande na América Latina que sua normalidade disputa a soberania com o tipo ideal de moral cívica, que é também compartilhada pelos cidadãos. Tudo se passa como se a disjunção entre sociedade e Estado se estendesse para a lógica em uso da moralidade privada. As pessoas nesse caso "abstraem" o Estado quando se trata de realizar seus próprios interesses privados e produzem justificativas morais que reforçam essa separação. A propina, em pequena ou grande escala, ganha uma estranha normalidade no âmbito das relações de famílias e firmas com o Estado, seja com a sua base tributária, seja com o seu sistema político. A propina, assim como a sonegação fiscal, é ao mesmo tempo praticada e denunciada. Representações sociais de "hipocrisia" situam os atores como sujeitos sociais contraditórios, que pela manhã frequentam a corrupção e à noite a denunciam.

De qualquer modo, é importante reconhecer a abrangência de uma modalidade de trocas que incorpora cálculos estratégicos de poder e de relações de força que ultrapassam o convencional cálculo econômico. Inspirado na ideia weberiana de "capitalismo político ou aventureiro", que realiza seus ganhos com base na violência e na imposição compulsória da troca, cunhei o conceito de "mercadorias políticas" para escapar das armadilhas normativas que aquela "hipocrisia" criava, do ponto de vista metodológico, para a compreensão do que realmente se passa nessas transações. ${ }^{8}$

E o que se passa? O que se passa é simplesmente um conjunto variável de ilegalismos de diferentes graus de tolerância, que em geral escapam ou não interessam ao processo estatal de criminalização e que viabilizam, por fora do controle estatal, trocas de mercadorias políticas de diferentes valores, desde aquelas produzidas por conveniência das partes, como o clientelismo e o tráfico de influência, até as extremas, que praticamente tornam compulsória a troca de mercadorias políticas, como a chantagem, a extorsão e proteção sob ameaça. $\mathrm{O}$ sicariato talvez seja a sua forma típico-ideal. Mas em geral a forma mais frequente de mercadorias políticas, embora quase sempre clandestina, é a que interessa a ambas as partes, abstrai o Estado e precifica relações de poder. Tornaram-se abundantes com a criminalização das drogas cuja produção ativa a economia dos países andinos e cujo consumo não cessa de crescer nas cidades latino-americanas.

A economia das drogas não só fortaleceu ainda mais a oferta de mercadorias políticas de proteção de seu circuito, da produção ao consumo, como permitiu o financiamento regular de agrupamentos e redes de diferentes tamanhos, tipos e nomeações (quadrilhas, pandillas, bandas, combos, maras, facções, cartéis) que passaram a operar em territórios disputados ao Estado. Em diferentes escalas, a base territorial de atuação desses agrupamentos e redes, protegida em vários casos por armamento pesado, armas defensivas de guerra, cresceu interligando os presos do sistema penitenciário de cada país com o chamado "mundo 
do crime". Esse processo vem transformando o modo específico de punição do Estado moderno, o encarceramento, em uma das principais bases de recrutamento e organização de redes criminais de amplo espectro, como no Brasil as facções do Comando Vermelho (CV) e do Primeiro Comando da Capital (PCC), que disputam o controle do atacado e a proteção do varejo do comércio de drogas ilícitas, entre outros bens ilegais. No Brasil, por exemplo, a taxa de encarceramento quadruplicou em trinta anos, o mesmo período em que cresceu extraordinariamente o poder dessas redes criminais.

Já temos hoje um grande volume de pesquisas e estudos sobre a violência na América Latina e no Caribe, mas há muita desigualdade de qualidade do trabalho de campo, abrangência, transparência nos dados oficiais e capacidade analítica. Grande parte dos problemas de transparência de dados oficiais, por exemplo, resulta da baixa qualidade dos dados produzidos pela polícia e pelo judiciário dos países latino-americanos, quase que sem exceção. Não é possível separar a atuação do controle social sobre a violência da própria violência como um todo. Essa é uma das principais dimensões do que tenho chamado de acumulação social da violência.

É preciso, no entanto, distinguir as abordagens que resultam da criminologia daquelas que pretendem construir uma antropologia ou uma sociologia da violência. As metodologias apresentam diferenças significativas e efeitos práticos diversos. A abordagem criminológica é interdisciplinar e mais próxima do ponto de vista biopolítico do Estado moderno, quer contribuir normativamente para o aperfeiçoamento dos diagnósticos e dos métodos de prevenção e controle da criminalidade violenta. Há uma abundante literatura criminológica sobre causas, análise situacional, ecológica e econômica, modelos de análise sobre crime organizado, avaliação de políticas públicas etc., tudo isso visando aplicações em projetos preventivos ou de dissuasão punitiva. Usa-se e abusa-se das estatísticas oficiais ou produzidas em surveys de diferentes formatos.

Uma antropologia da violência afasta-se inteiramente desse modelo, seja porque não incorpora a normatividade na análise, seja porque prefere contextualizar a compreensão do que é recortado pela sociedade mais abrangente como violência. A ênfase na etnografia e a preferência pelo trabalho de campo qualitativo também afastam a abordagem antropológica da maior parte dos trabalhos de base criminológica. Finalmente, a sociologia da violência tem pretendido construir uma ponte crítica entre a criminologia convencional e a antropologia da violência, utilizando-se de diferentes métodos para buscar uma aproximação mais abrangente sobre a violência na América Latina, interligando violência e soberania, violência e mercados e violência e construção social do crime nas sociedades latino-americanas.

O grande desafio que se coloca hoje para essa área de pesquisas é avançar - com base nos resultados empíricos alcançados até agora - no plano conceitual, abandonando velhas e surradas fórmulas, seja da criminologia convencional, seja 
das palavras que naturalizaram na esfera do direito a enorme complexidade desse campo de estudos. Livrar-se da explicação fácil e das causalidades lineares exigirá não perder de vista a crítica das instituições, as transformações nos modelos de controle social e a historicidade dos problemas que se pretende compreender.

Grande parte desses estudos e pesquisas está ancorada na iminência das demandas de solução para a violência ou buscam servir de base para políticas de segurança pública renovadas. Há várias experiências relativamente bem-sucedidas no nível local, que conseguiram controlar o aumento ou até mesmo reduzir o volume de homicídios e outras violências em cidades latino-americanas. No entanto, o que mais cresce e mais se torna abrangente é uma estranha aliança entre tecnologias de poder preventivo, com base na vigilância eletrônica e digital e a tradicional política dos confrontos armados e repressivos nas áreas urbanas pobres e periféricas ou nas áreas rurais afastadas. Nos centros de interesse do capital, vigilância dia e noite por câmeras e outros apetrechos tecnológicos; nas margens do Estado, porrada, abusos e assassinatos como forma de controle de mercados ilegais e agrupamentos juvenis que exploram mercadorias políticas. Não bastasse isso, também agentes do Estado, policiais ou não, passam cada vez mais a oferecer mercadorias políticas, tirando vantagem da demanda de proteção tanto nos centros de interesse do capital quanto nas margens desprotegidas do Estado.

Grupos paramilitares, milícias parapoliciais, esquadrões da morte, grupos de extermínio - todas essas formações nascem do Estado e dele se alimentam de poder e impunidade. Todas essas ligações perigosas entre a lógica do mercado e os recursos de poder recuperados do Estado, associando sujeição criminal das populações socialmente excluídas, mercados informais e ilegais e mercadorias políticas constituem a dimensão central da acumulação social da violência que opera nos interstícios da separação entre sociedade e Estado na América Latina.

\section{Disjunções e diferenciais estatais ou desigualdade de fora a fora}

Não pude deixar de observar, certa vez, numa mesa-redonda de que participava, após ouvir as terríveis descrições do que a polícia carioca fazia cotidianamente, um renomado jurista norte-americano, surpreso, perguntou perplexo, "but... and the rule of law"? Ele queria dizer em bom português: mas ... e a lei? Não há império da lei? Não se segue a lei? A lei não governa?

Não é de hoje que se tenta definir o que acontece em vários segmentos do Estado na América Latina, mesmo quando em regime democrático, e que parece sem conformidade com a expectativa de "agir conforme a lei". Em certas situações, as práticas revolvem como numa dança de cadeiras em que apenas num caso se age conforme a lei, todos os outros aguardando a sua vez ou simplesmente se afastando do jogo legal. Guillermo O'Donnel (2000) definiu-o como uma "cidadania de baixa intensidade". Teresa Caldeira e James Holston (1999) entenderam a democracia na América Latina como "incompleta e disjuntiva". Anthony Pereira (1997), ao reconhecer que a lei é aplicada diferencialmente, 
chamou-lhe de "liberalismo elitista". Donna Goldstein (2003) vê correlação entre cidadania e classes sociais e Angelina Peralva (2000) viu "uma cultura libertária e liberal que é por princípio desconfiada do Estado e das instituições e que tornou-se a patologia própria da democracia brasileira". Para ela, a fragilidade da relação com a lei se explica por uma tradição histórica de longo curso, que identificou a lei ao poder e à opressão. Caldeira e Holston (1999) chegaram a apontar a permanência "de um padrão cultural que associa ordem e autoridade com o uso da violência, e que contribui para a deslegitimação do sistema de justiça e do império da lei (rule of law)".

Há não só uma diferencial de tratamento das populações nas práticas policiais e nas sentenças judiciais como a desigualdade invade os próprios parâmetros legais, reconhecendo na prática o que a lei maior proíbe. Do mesmo modo, entre o que a lei literalmente afirma e as práticas negam, abre-se toda uma rede de possíveis interpretações, a critério da subjetividade de policiais, procuradores e juízes, que reproduzem no plano das práticas o que na sociedade se faz habitualmente, mesmo sendo contra a lei.

\section{Marginal, marginais}

Há um retorno, ainda tímido e no mínimo curioso, da categoria "marginalidade" nas ciências sociais contemporâneas (Wacquant, 2009; Young, 2004; Murphy, 2014). A categoria havia sido banida da sociologia urbana desde fins dos anos 1980 e substituída por uma nova categoria, supostamente mais esclarecida, a de "exclusão social". Criticava-se o modelo espacial "centro-periferia" em proveito de uma topologia fora-dentro, "inclusão versus exclusão". O que estava em jogo era a crítica do pressuposto marxista do primeiro modelo, baseado na noção de "populações marginais" e de "exército industrial de reserva" da força de trabalho, tal como proposto em $O$ capital, de Marx. O capitalismo já não era mais o mesmo e a expulsão dos trabalhadores deixava de ser somente funcional para a regulação dos salários para se tornar definitiva, inteiramente excludente e subordinada à automação sob a égide do capital financeiro. Não se marginalizava mais, se excluía definitivamente a força de trabalho excedente do neoliberalismo. A pobreza urbana ganhava outra dimensão, menos provisória, mais permanente.

No Brasil, a categoria "marginal" havia atravessado antes outras aventuras heurísticas, menos marxistas e mais herdeiras da sociologia da "Escola de Chicago", ainda que sua apropriação jornalística tenha produzido aqui um significado desviante. A publicação do livro O homem marginal. Estudo de personalidade e conflito cultural de Everett V. Stonequist (1958), pela Livraria Editora Martins, em 1948 (a primeira edição norte-americana havia sido de 1937), desencadeou uma apropriação jornalística do sentido de "marginal", no Brasil, que marcou toda uma época e ainda produz seus efeitos. No livro de Stonequist eram desenvolvidas ideias sobre tipos humanos provenientes de migrações e que se estabeleciam entre duas formações culturais, a sua e a que o recebia: ciganos, judeus, negros africanos ex-escravos, cristãos convertidos na Ásia etc. Robert E. 
Park prefaciara o livro porque Stonequist fora seu aluno e trabalhava essas ideias cuja originalidade Park encontrara no famoso ensaio sobre "O estrangeiro", de Simmel. O marginal do livro é a personalidade que está no limite entre duas culturas, a sua e a do lugar para onde migrou. No Brasil, entretanto, o "marginal" virou sinônimo de bandido, num viés típico de quem viu o título do livro mas não o leu. Mas havia sentido na apropriação: o bandido era marginal à sociedade, marginal às leis ("fora da lei") e marginalizado do ponto de vista econômico-social. A associação entre pobreza urbana, marginalidade social e criminalidade, nas representações sociais, cuidou de consolidar o novo sentido de "marginal". Quem pesquisa os jornais populares dos anos 1950 e 1960 verificará como a alcunha de "marginal" substituirá gradualmente a antiga alcunha de "malandro" nas reportagens que observavam as mudanças no padrão da criminalidade urbana no Rio e em São Paulo no início dos anos 1960.

$\mathrm{Na}$ sociologia urbana latino-americana os usos da categoria referiam-se à marginalidade econômica e social, às favelas e aos trabalhadores informais, $\mathrm{o}$ mesmo significado que agora retorna em alguns estudos e pesquisas. Há no entanto uma diferença crucial e uma disjunção entre os dois tempos.

A publicação de $O$ mito da marginalidade, de Janice Perlman (1977), com quase nenhuma referência à violência nas favelas pesquisadas no Rio de Janeiro do final dos anos 1960, e o retorno que a autora faz ao assunto quarenta anos depois em Favela. Four decades of living on the edge in Rio de Janeiro (Perlman, 2010) é ilustrativo de nosso ponto. O que a autora chama, nos dois livros, de "a ideologia da marginalidade" é um dos efeitos daquela apropriação que transformou marginal em bandido. Mas a ideologia da marginalidade nada tem a ver com os usos acadêmicos da categoria de marginalidade, seja no sentido socioeconômico, de origem neomarxista, seja no sentido de Robert Park e da Escola de Chicago. E não foi por esse sentido ideológico que a categoria foi abandonada na sociologia urbana.

O recente retorno da categoria de marginal e marginalidade nas ciências sociais também não tem mais nada a ver, seja com o antigo sentido da Escola de Chicago, seja com o sentido neomarxista das "populações marginais", nem tampouco com a ideologia da marginalidade (que, aliás, ainda continua vigente em várias partes da América Latina). O novo sentido de marginal recupera apenas parte do sentido original da Escola de Chicago e provém do avanço dos movimentos identitários e quer revelar o processo de estigmatização que "marginaliza" negros, ex-presidiários, homossexuais, migrantes, mulheres de certas regiões. Mas há também uma outra revivescência do conceito, a partir dos trabalhos da antropóloga Veena Das e D. Poole (2004) sobre o que chamam de "margens do Estado". Nas novas margens não estamos mais nem na topologia espacial de centro e periferia, nem na de dentro e fora. Agora estamos no que pode ser chamado de "franjas" do Estado, um lugar institucional jurídico-político e também econômico em que o Estado perde ou não quer deter a mesma centralidade 
ativa que o caracteriza nos lugares em que é percebido como ator central. As “margens" agora não são nem geográficas nem includentes/excludentes, mas móveis na linha do que o Estado “deixa pra lá”, isso é, as áreas onde atua plenamente a exceção. É nesse novo sentido que também a marginalidade retorna à pauta sociológica contemporânea, como um lugar em que se "deixa morrer".

\section{Margens do Estado, exceção e democracias violentas}

Piedade é um tradicional bairro de classe média baixa do subúrbio da zona norte do Rio de Janeiro. Lá se localizam, entre igrejas e velhos jardins, o tradicional Presídio de Água Santa e um grande complexo educacional do Estado, a Faetec. Como outros bairros da zona oeste e norte, virou "margem do Estado". Milícias controlam as ruas e cobram do comércio local taxas de proteção. A extorsão é praticada abertamente, em carros da própria polícia. A "lei do silêncio" é seguida tanto ou mais do que a praticada em territórios urbanos controlados por quadrilhas de traficantes de drogas. O novo fenômeno se espalha muitas vezes de forma difusa, não concentrada. Ruas de Copacabana, o famoso bairro da zona sul do Rio, são controladas por indivíduos que cobram, fora do horário legal de atuação da prefeitura, o estacionamento de carros nas vias públicas. Para não serem importunados, eventualmente pagam proteção à polícia para continuar atuando, inclusive como pequenos traficantes. Numa dessas ruas, um desses "flanelinhas" foi preso por tráfico e pôs a sua mulher para controlar os negócios em sua ausência. As ruas são demarcadas por áreas sob controle de um ou outro indivíduo, de modo a evitar competição e conflito pelo controle local. Os motoristas pagam pelo estacionamento muitas vezes por receio de que esses "guardadores" possam se vingar produzindo danos nos seus carros. Em alguns bairros e condomínios da Barra da Tijuca já se conhece a transição desse tipo de formação individualizada para uma formação coletiva armada de oferta compulsória de proteção ao comércio local e mesmo aos condomínios residenciais. Não é exato atribuir-se tudo isso à "ausência do Estado" ou à "fraqueza do Estado". Agentes públicos de variadas posições transitam ou moram nessas ruas e paradoxalmente não interferem ou, quando o fazem, tiram proveito, como no caso de policiais locais. O que há de "marginal" nisso tudo? O PCC, assim como antes o $\mathrm{CV}$, é produto dessa "marginalidade". As "margens do Estado" também podem caber dentro do Estado.

Estudando o caso de São Paulo, Graham D. Willis chega a sugerir que "pintar o PCC como apenas marginal é não compreender seja a realidade empírica da cidade como também perder de vista os meios que grupos como esse tem usado para remoldar as relações sociais e a própria cidade". Antes de Willis, Gabriel Feltran já havia sugerindo uma síntese compreensiva de todas essas clivagens entre segregação social, pobreza, exclusão e sujeição criminal:

[Há] um tipo específico de coexistência, no plano do regime político e no plano das relações sociais, entre ordenamentos de lógicas internas distintas. O primeiro é o código universalista da política e o segundo o código ins- 
trumental da violência, ambos constitutivos e necessários para a reprodução de um modelo de funcionamento institucional e social marcado pela manutenção de um mundo público formalmente democrático, e uma dinâmica de distribuição dos lugares sociais marcada por extrema hierarquização. (Feltran, 2011, p.337)

Em seu argumento, inspirado em L. A. Machado da Silva, Feltran afirma que a "característica política fundamental que a sustenta (essa dupla ordem) é a de propiciar restrição de fato do acesso universal ao direito de ter direitos embutida na consolidação de um regime político formal universalista” (ibidem).

A pergunta que o jurista nos fez na mencionada mesa-redonda: “[...] and the role of law'? é bastante pertinente e sintomática, tem levado muitos pesquisadores - brasileiros e estrangeiros - a pensarem que a lei não prevalece, que a lei não rege a sociedade, que o controle social institucionalizado não funciona. Daí para se pensar que o Estado é fraco, ou que não há Estado, ou que em certas áreas - as brown areas de O’Donnel, 1986 - há total “ausência de Estado” basta um passo (Goldstein, 2003; Arias, 2003 . Aparentemente não passa pela cabeça de ninguém que o Estado não pode estar ausente, que essa é a sua forma de presença, o modo eficaz como funciona na América Latina, mesmo sob regime democrático. Bem sei que esse é um argumento funcionalista, mas é também evidente que esse tipo de Estado só é “desviante” (incompleto, fraco, inoperante...) se tomarmos como tipo ideal de Estado democrático aquele que persevera, após a Segunda Grande Guerra, no que O’Donnell chamou de o "Noroeste” do planeta. Dois autores chegaram perto dessa mesma conclusão, digamos, realista, Desmond Arias e Daniel Goldstein, quando propuseram o conceito de "pluralismo da violência". No entanto, ainda assim, continuaram com o império da lei na cabeça quando pediram para que se ponha a democracia latino-americana entre parênteses como condição para se entender sua proposta analítica. Não é preciso: na lei brasileira, as Forças Armadas são a última instância legal garantidora da lei e da ordem social, o que significa que elas tem a tutela, em última instância, da República brasileira. Essa foi uma conquista que os militares obtiveram ao longo da República Velha através de várias rebeliões, com o apadrinhamento de uma ditadura (Vargas) e finalmente com a conquista do poder (1964-1985). Após a redemocratização, conseguiram que se inscrevesse na Constituição de 1988 que são as Forças Armadas que asseguram, em última instância, o direito e a ordem pública, o que significa - para bom entendedor da história brasileira recente - que o povo não é a última instância do poder, mas as Forças Armadas. ${ }^{9}$

$\mathrm{O}$ que significa tudo isso? Como se compreende a disjunção do Estado e da sociedade brasileira (e também, por extensão histórica, latino-americana) nesse caso?

Em primeiro lugar, é preciso reconhecer que no plano das ideias a sociedade latino-americano transita há várias décadas de um sistema de crenças hierárquico-estamental para um sistema de crenças igualitário-individualista (DaMatta, 1979; Peralva, 2000; Lima, 2009) e que o efeito disso, numa sociedade de 
consumo de massa, tem sido produzir jovens individualistas-hierárquicos com demandas igualitárias, mas sem possibilidade objetiva de alcançar os seus interesses, já que a estrutura econômico-social permanece preservando uma resistente barreira à mobilidade social, principalmente nas dimensões de etnia ou raça, gênero e acesso a direitos, impregnadas de pobreza urbana, segregação social e privação relativa. O resultado é uma acumulação social de desvantagens amplamente distribuída em praticamente todas as cidades latino-americanas, com uma geografia humana de favelas, comunas, barrios e conjuntos habitacionais de periferia sem paralelo - nessa dimensão - com os protótipos democráticos europeus e norte-americanos. Talvez por isso, autores como Desmond Arias e Daniel Goldstein tenham podido escrever, com propriedade, sobre as "democracias violentas" da América Latina. Aí está o paradoxo - como uma democracia pode ser adjetivada de violenta sem perder o significado de democracia?

\section{Notas}

1 A maior parte deste artigo foi apresentada na forma de conferência na Universidade da Califórnia em Santa Barbara, nos Estados Unidos, e, em versão um pouco diferente, em seminário internacional no Colégio de Michoacán, no México, ambos em outubro de 2017. Uma parte nova, inédita, foi acrescentada à segunda parte, especialmente sobre o Brasil. Agradeço a Paul Amar, do Programa de Estudos Globais da UC em Santa Bárbara e a Santiago Maldonado, do Colégio de Michoacán, os convites para as referidas conferências.

2 Os dados para o Brasil e América Latina são divulgados oficialmente por diferentes agências. No Brasil, óbitos por agressão são divulgados pelo Sistema de Informação da Mortalidade do Ministério da Saúde e dados sobre criminalidade em geral pela Secretaria Nacional de Segurança Pública e pelo Anuário do Forum Brasileiro de Segurança Pública. Os dados gerais para a América Latina, inclusive Brasil, podem ser obtidos junto a várias agências das Nações Unidas, como PNUD, Unodc e Alto Comissariado para os Direitos Humanos.

3 Esse argumento é, evidentemente, um corolário da definição de Estado como detentor monopólico do uso legítimo da força para a administração da justiça. Sobre a incapacidade dos Estados latino-americanos, em geral, de regularem ou controlarem a violência em seus territories há ampla bibliografia (cf. Imbush; Misse; Carrión, 2011).

4 Há vasta bibliografia sobre esse tópico. Ver, por exemplo, Méndez et al. (2000); Arias e Goldstein (2010); Holston (2008); Fischer et al. (2014).

5 Sobre a questão da soberania em sociedades pós-coloniais, ver Hansen e Stepputat (2001; 2005); Vardoulakis (2013); Sarat e Culbert (2009).

6 Sobre sujeição criminal, ver Misse (2018). Sobre necropolitica, ver Mbembe (2018); sobre “deixar morrer", ver Sarat e Culbert (2009).

7 Creio que Graham D. Willis (2015) exagera no título de seu livro The Killing Consensus. Há mais disputa que consenso nesse caso.

8 Sobre o conceito de "mercadorias políticas", ver Misse $(2013 ; 2014)$.

9 Para uma argumentação mais equilibrada dessa tutela, ver Zaverucha (1994). 
Referências

ARIAS, E. D. Drugs \& Democracy in Rio de Janeiro. Trafficking, Social Networks \& Publica Security. Chapel Hill, The University of North Carolina Press, 2003.

ARIAS, E. D.; GOLDSTEIN, D. M. (Ed.) Violent Democracies in Latin America. Duke University Press, 2010.

CALDEIRA, T.; HOLSTON, J. Democracy and Violence in Brazil. Comparative Studies in Society and History, v.41, p.691-729, 1999.

DAMATTA, R. Carnavais, malandros e heróis. Para uma sociologia do dilema brasileiro. Rio de Janeiro: Zahar Editores, 1979.

DAS, V.; POOLE, D. Anthropology in the Margins of the State. Santa Fe: New School of American Research, 2004.

FELTRAN, G. S. Fronteiras de tensão. Política e violência nas periferias de São Paulo. São Paulo: Editora Unesp, 2011.

FISCHER, B.; MCCANN, B.; AYUERO, J. (Ed.) Cities from Scratch: Poverty and Informality in Urban Latin America. Duke University Press, 2014.

GOLDSTEIN, D. M. Laugther Out of Place. Race, class, violence, and sexuality in a Rio Shantytown. University of California Press, 2003.

HANSEN, T. B.; STEPPUTAT, F. (Ed.) States of Imagination. Ethnografic explorations of Postcolonial State. Duke University Press, 2001.

. (Ed.) Sovereign bodies. Citizens, migrants and states in postcolonial world. Princeton University Press, 2005.

HOLSTON, J. Insurgent Citizenship: Disjunctions of Democracy and Modernity in Brazil. Princeton University Press, 2008.

IMBUSCH, P. "The concept of violence", in Wilhelm Heitmeyer and John Hagan ed. International Handbook of Violence Research, Kluwer Academics, v.1, p.13-40, 2003.

IMBUSCH, P.; MISSE, M.; CARRIÓN, F. Violence Research in Latin America and the Caribbean: A Literature Review. International Journal of Conflict and Violence, v.5, p.87-154, 2011.

LIMA, R. K. de. Ensaios de antropologia e de direito. Rio de Janeiro: Lumen Juris, 2009.

MACHADO DA SILVA, L. A. Fazendo a cidade. Trabalho, moradia e vida local entre as camadas populares urbanas. Rio de Janeiro: Mórula Editorial, 2016.

MBEMBE, A. Necropolitica. Biopoder, soberania, estado de exceçãoo, política da morte. São Paulo: N-1 Edições, 2008.

MÉNDEZ, J. E.; O’DONNELL, G.; PINHEIRO, P.S. (Org.) Democracia, violência e injustiça. O não-Estado de Direito na América Latina. São Paulo: Paz e Terra, 2000.

MISSE, M. Malandros, marginais e vagabundos \& a acumulação social da violência no Rio de Janeiro. Rio de Janeiro, 1999. Tese (Doutorado em Ciências Humanas: Sociologia) - Instituto Universitário de Pesquisa do Rio de Janeiro. Rio de Janeiro, 1999.

. Estado y mercados ilegales en Latinoamérica: reflexiones a partir del concepto de mercancía política. In: RAMÍREZ, J. G. (Org.) Economía criminal y poder político. Medellin: Universidad Eafit, 2013. p.9-32. 
MISSE, M. Mercadorias Políticas. In: LIMA, R. S. de; RATTON, J. L.; AZEVEDO, R. (Org.) Crime, polícia e justiça no Brasil. São Paulo: Contexto, 2014. p.200-30.

MISSE, M. Violência e Teoria Social. Dilemas: Revista de Estudos de Conflito e Controle Social, v.9, n.1, p.45-63, 2016.

Una identidad para el exterminio. Escritos sobre sujeción criminal. Temuco, Chile: Universidad de la Frontera, 2018.

The Puzzle of Social Accumulation of Violence in Brazil: Some Remarks. Journal of Illicit Economies and Development, v.1, n.2, p.177-82, 2019.

MURPHY, E. In and Out of the Margins. In: FISCHER, B. et al. (Ed.) Cities from Scratch. Poverty and Informality in Latin America. Durham, NC: Duke University Press, 2014. cap.2, p.68-100.

O’DONNELL, G. Contrapontos. Autoritarismo e democratização. Editora Biblioteca Vertice, 1986.

"Poliarquias e a (in)efetividade da lei na América Latina: uma conclusão parcial”, in Juan E. Méndez, Guillermo O’Donnell e Paulo Sérgio Pinheiro, orgs. Democracia, violência e injustiça. O Não-Estado de Direito na América Latina. São Paulo, Paz e Terra, 2000.

Dissonâncias. Críticas democráticas à democracia. Rio de Janeiro: Editora UFRJ, 2017.

PERALVA, A. Violência e democracia. O paradoxo brasileiro. São Paulo: Paz e Terra, 2000.

PEREIRA, A. Elitist Liberalism: Citizenship, State Violence, and the Rule of Law in Brazil. Paper presented at the XX International Congress of the Latin American Studies Association. April, Guadalajara, Mexico. 1997.

PERLMAN, J. O mito da marginalidade. Rio de Janeiro: Paz e Terra, 1977.

Favela. Four decades of living on the edge in Rio de Janeiro. Oxford University Press, 2010.

SARAT, A. ; CUlbERT, J. (Ed.) States of Violence. War, Capital Punishment and Letting Die. Cambridge University Press, 2009.

SCHINKEL, W. Aspects of Violence. A Critical Theory. S. 1.: Palgrave-Macmillan, 2010. STONEQUIST, E. O homem marginal. São Paulo: Livraria Editora Martins, 1958.

VARDOULAKIS, D. Sovereignty and its Other. Toward the Dejustification of Violence. Fordham University Press, 2013.

WACQUANT, L. Urban Outcaste. A Comparative Sociology of Advanced Marginality. Polity, 2009.

WALBY, S. Violence and society: introduction toa n emerging field of sociology. Current Sociology, v.61, n.2, 2013.

WILLIS, G. D. The Killing Consensus. Police, Organized Crime, and the Regulation of Life and Death in Urban Brazil. University of California Press, 2015.

YOUNG, A. The Minds of Marginalized Black Men. Princeton University Press, 2004.

ZAVERUCHA, J. Rumor de sabres. Controle civil ou tutela militar? São Paulo: Ática, 1994. 
RESUMO - O artigo examina, a partir de uma variada bibliografia, o que identifica como alguns dos principais problemas analíticos nas pesquisas sobre violência na América Latina. A disjunção entre Estado e sociedade, a conciliação impossível entre democracia e violência e os desafios da pesquisa empírica nessa área temática são tratados na forma de uma introdução a um projeto que o autor está desenvolvendo sobre o mesmo tema. PALAVRAS-CHAVE: Violência, Criminalidade, Democracia, América Latina.

ABSTRACT - Based on extensive bibliography, the article examines what it identifies as some of the main analytical problems in the research on violence in Latin America. The disjunction between State and society, the impossible conciliation between democracy and violence, and the challenges of empirical research in this subject area are treated as an introduction to a project that the author is developing on the same theme.

KEYWORDS: Violence, Criminality, Democracy, Latin America.

Michel Misse é professor titular de Sociologia do Instituto de Filosofia e Ciências Sociais da Universidade Federal do Rio de Janeiro, coordenador do Núcleo de Estudos da Cidadania, Conflito e Violência Urbana da UFRJ e editor de Dilemas - Revista de Estudos de Conflito e Controle Social. @ - michelmisse@gmail.com / https://orcid.org/0000-0003-3815-8674

I Instituto de Filosofia e Ciências Sociais, Universidade Federal do Rio de Janeiro, Rio de Janeiro, Brasil.

Recebido em 24.6.2019 e aceito em 18.7.2019. 